\title{
Conexões entre o Planejamento Urbano e a Cidade Saudável
}

Dossier DE PESQUISA : CidADE SAUdÁVEL

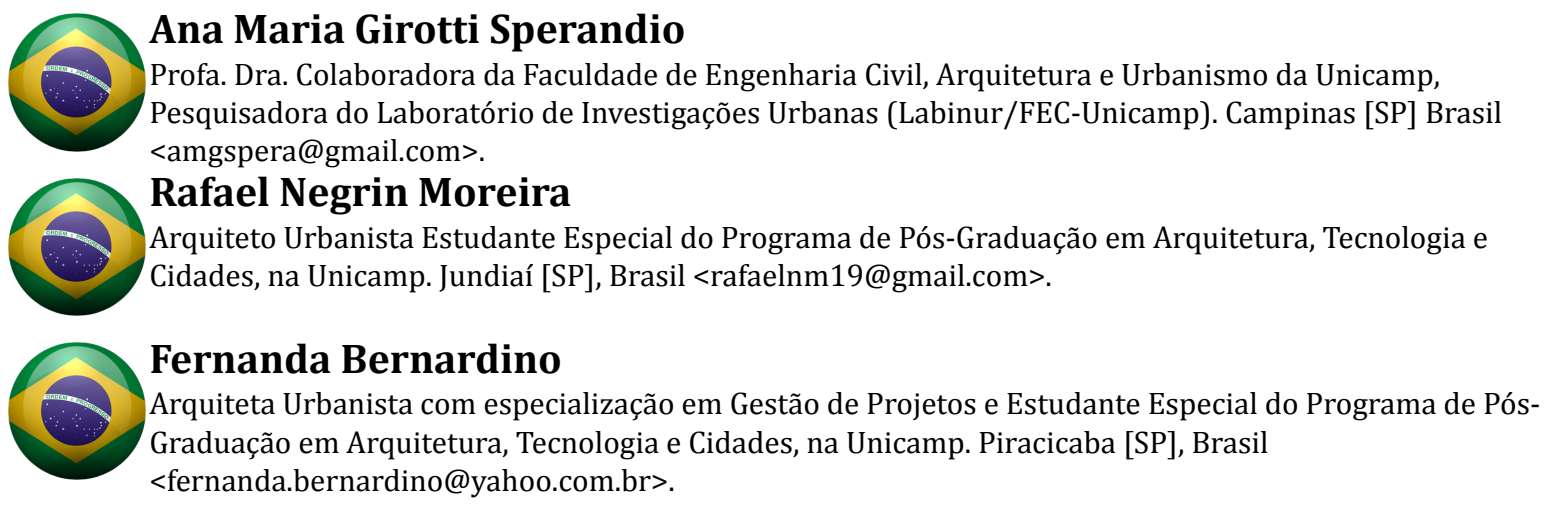

\section{Resumo}

Uma cidade para ser saudável deve considerar sua história, as gerações futuras, as potencialidades e necessidades locais através da valorização da participação social para o desenvolvimento de estratégias intersetoriais promovidas pelo planejamento urbano visando à melhoria da qualidade de vida de seus habitantes. Por meio da abordagem qualitativa e descritiva, foi possível realizar um percurso metodológico na cidade potencialmente saudável de Conchal, interior de São Paulo, proposto pela disciplina de Planejamento Urbano como Promotor da Cidade Saudável, da FEC/UNICAMP, com intuito de conhecer a horta comunitária, a academia da saúde e a central de reciclagem e desenvolver um ensaio sobre princípios, valores e impactos para o planejamento de tais cidades. A pesquisa permitiu identificar por meio das evidências e eficácia destes projetos, o bem-estar e a felicidade da comunidade. Neste sentido, conclui-se com este estudo de caso que o senso de pertencimento, fortalecimento da participação social, políticas públicas inclusivas, governança, ações interdisciplinares e intersetoriais e a equidade, são fatores significativos para a promoção das cidades saudáveis.

\section{Palavras-chave}

Planejamento urbano. Cidade potencialmente saudável. Participação social.

\section{Connections between Urban Planning and Healthy City}

\begin{abstract}
A city to be healthy should consider the history, future generations, local potentialities and needs through the valorization of social participation for the development of intersectoral strategies promoted by urban planning aiming at improving the inhabitant's quality of life. Through a qualitative and descriptive research, it was possible to realize a methodological course in the potentially healthy city of Conchal, in São Paulo, proposed by the discipline of Urban Planning as a Promoter of the Healthy City of FEC/UNICAMP, in order to know a community garden, a health gym and a recycling center to develop an essay on principles, values and impacts for the planning of such cities. The research enabled to identify through the evidence and effectiveness of these projects, the well-being and happiness of the community. Therefore, it concludes with this case study that the sense of belonging, strengthening of social participation, inclusive public policies, governance, interdisciplinary and intersectoral actions and equity, are significant factors for the promotion of healthy cities.
\end{abstract}

\section{Keywords}

Urban planning. Potentially healthy city. Social participation. 


\section{Introdução}

O planejamento enquanto ferramenta para melhoria da qualidade de vida deve propor estratégias para pensar as cidades de maneira sustentável, buscando atender a demanda atual sem comprometer as gerações futuras. Para tanto, a promoção da saúde é fundamental para o desenvolvimento econômico, social, ambiental e cultural de um país e o planejamento urbano atua como determinante estrutural da saúde através de suas instituições, as micro e macro políticas. Com o objetivo de reconstruir a conexão entre as ações, projetos e políticas do planejamento urbano e a saúde pública, criou-se o programa de Cidades Saudáveis (Corburn, 2017).

Para Certeau (1998), a cidade é composta pelo projeto urbanístico, planejamento e desejos de funcionamento. De outro lado, é reestruturada continuamente pela vida urbana, configurando uma relação simbiótica. Assim sendo, a cidade saudável é aquela que aprende com a história, reconhece as potencialidades locais, fortalece aspectos físico-sociais dos ambientes e a autonomia de seus habitantes por meio de estratégias de promoção à saúde em um processo contínuo e equitativo.

De acordo com Sperandio et al. (2016, p.1), a prática de pensar o planejamento urbano em concordância com o exercício de projetar cidades de maneira multi e transdisciplinar, se traduz em novas perspectivas dentro do conhecimento cientifico e acadêmico. Para tanto, a atuação da Universidade através de profissionais e pesquisadores na área da Engenharia, Arquitetura, Meio Ambiente e Saúde com a compreensão da realidade e levando em consideração novas concepções insurgentes de planejamento, pode contribuir para a ascensão de parâmetros saudáveis na Cidade.

A Rede de Municípios Potencialmente Saudáveis (RMPS) criada no ano de 2003 possui 50 municípios participantes e atua nesta perspectiva. É um projeto para desenvolver politicas públicas, pautado no entrelaçamento de saberes e práticas pensadas a partir das realidades e necessidades locais.

De acordo com Brandão (2010), o que define um município potencialmente não são índices evidentes de desenvolvimento humano e sim, aquele que se empenha em melhorar a qualidade de vida de seus habitantes através do fortalecimento de uma rede coesa formada pelo poder público e a sociedade local.

Neste contexto, a cidade de Conchal no interior de São Paulo com aproximadamente 27 mil habitantes, destaca-se por algumas ações de promoção da saúde realizadas pelo planejamento urbano e coordenadas pelo Poder Público Municipal que apresentam características de governança, representatividade, inclusão, cooperação e ativa participação social.

\section{Objetivo}

Descrever, identificar e sistematizar as ações coletivas e experiências que valorizem princípios e valores do planejamento urbano para uma cidade saudável.

\section{Metodologia}

Durante visita agendada pela disciplina de Planejamento Urbano como Promotor da Cidade Saudável, da UNICAMP, os alunos tiveram a oportunidade de conhecer três projetos assistidos pelo Laboratório de Investigação Urbana (LABINUR) da Faculdade de Engenharia Civil, Arquitetura e Urbanismo da Universidade Estadual de Campinas (FEC/UNICAMP) que se tornaram objeto deste relato de experiência, sendo eles: horta comunitária, academia da saúde e central de reciclagem. 0 campo de realização deste estudo foi na cidade de Conchal, localizada a $180 \mathrm{~km}$ de São Paulo e que há oito anos faz parte da Rede de Munícipios Potencialmente Saudáveis (RMPS).

Este relato da experiência possui caráter exploratório, descritivo e caracteriza uma abordagem qualitativa. As informações identificadas por meio de depoimentos de diferentes agentes (comunidade, trabalhadores e gestores públicos), fotografias e percepções visuais dos estudantes estarão descritas durante o percurso deste artigo. 
Por meio de ações pontuais e coletivas, dentro da escala urbana da cidade de Conchal, foi desenvolvido um ensaio sobre princípios e valores necessários para o planejamento de uma cidade saudável com investigação sobre sua reverberação em macro escala. Pretendeu-se ainda discorrer sobre como identificar, através de evidências e da eficácia de tais projetos, o bem-estar, a qualidade de vida e a felicidade da comunidade.

Com as reflexões estabelecidas durante a disciplina ministrada de "Planejamento Urbano como Promotor de Cidade Saudável" no segundo semestre de 2018, a partir da leitura de "Políticas Integradas em Rede e a Construção de Espaços Saudáveis: boas práticas para a iniciativa do Rostos, Vozes e Lugares" e a revisão de outras bibliografias relevantes, como o Estatuto da Cidade (2001) e a Lei 8080 (1990), foi possível realizar uma visita guiada à cidade de Conchal [SP] para validar as experiências relatadas durante o aprendizado e, portanto, verificar a convergência entre a realidade observada e os métodos de planejamento.

Os projetos foram definidos pela professora da UNICAMP em conjunto com o grupo de conselho local da saúde e a visita foi realizada durante o dia 24 de outubro de 2018. A metodologia utilizada foi baseada nos preceitos do walkthrough, contando com um guia de observações e temas a serem abordados no diálogo junto à comunidade e gestores. 0 walkthrough, enquanto instrumento analítico colabora para a coleta de dados multidisciplinares do ambiente estudado em curto espaço de tempo e permite, a partir da situação atual do local, identificar seus pontos positivos e negativos, facilitando a familiarização e compreensão dos pesquisadores quanto à sua estrutura física. Por meio de um passeio e de um roteiro pré-estabelecido, a observação participante corroborou para o desempenho assertivo da avaliação contribuindo, de acordo com um olhar técnico, para o embasamento do processo (IPEA, 2015).

\section{Relato das experiências}

De acordo com o artigo $2^{\circ}$ da Portaria no 2.446 (2014), o objetivo fundamental da promoção da saúde é produzir saúde individual e coletiva, por meio de um trabalho colaborativo e multisetorial que conecte e responsabilize mutuamente todas as partes envolvidas no desenvolvimento de ações efetivas de proteção e justiça social. Sob a ótica da percepção da promoção da saúde como determinante para qualidade de vida, a experiência nos projetos de Conchal possibilitou debates entre os estudantes tanto nos percursos dentro da cidade, como no trajeto de volta à Universidade, bem como nas aulas posteriores à visita.

Na semana seguinte, os alunos da disciplina de pós-graduação estudaram os materiais adquiridos na visita como diálogos, fotos, locais, correlacionando as impressões, conversas, histórias e percepções obtidas em Conchal com os conceitos de promoção da saúde estabelecidos no Art. 2o da Portaria no 2.444 (2014), que redefine Política Nacional de Promoção da Saúde (PNPS) e com as disposições e premissas do Estatuto das Cidades (2001). Deste ensaio resultou um debate com uma seleção de palavras-chave que se tornaram alicerces para elaboração deste artigo e serão apresentados ao longo deste percurso em que as experiências servem de base para busca de evidências.

A apresentação das experiências abaixo ocorreu através das reflexões obtidas a partir dos diálogos com a comunidade, lideranças e gestores e com a observação de como as ações dentro da esfera de cada projeto que foram exteriorizadas em relação à cidade refletem positivamente na qualidade de vida de sua população.

\subsection{A horta comunitária}

Ao chegar ao Município uma observação física-territorial imediata começou a ilustrar evidências de uma cidade potencialmente saudável: as larguras das vias, a topografia plana e a presença de ciclistas.

Mesmo com o tempo chuvoso, a Servidora Municipal que recepcionou os alunos permitiu que os diálogos com os trabalhadores e o percurso investigativo fossem construídos com naturalidade a fim de compreender a operacionalização e dinâmica da horta. 
Naquele momento, cerca de dez pessoas trabalhavam no local e dentre as diversas abordagens realizadas, destaca-se a conversa com uma colaboradora do projeto que, desde 2011, cultiva em seu espaço alface, rúcula, agrião, coentro, manjericão, salsinha, cebolinha, couve, repolho dentre outras verduras e hortaliças. Comuns as outras histórias, após cuidar da mãe por vinte anos e mesmo com a saúde comprometida, a horticultora continua trabalhando no local diariamente em dois períodos. Notou-se que a motivação desta senhora vem de uma resiliência individual que se conectou com outras resiliências locais e ecoou em ações que vão além dos limites da horta e do bairro, refletindo a capacidade do projeto em ressoar qualidade de vida aos habitantes locais.

Não existem aparências ou superficialidade na horta, o que se vê ali são pessoas reais com desejos reais e determinação, que percebem o valor de uma alimentação saudável e livre de agrotóxicos como garantia de saúde, e que acreditam no resultado de um trabalho comunitário equitativo.

Nas abordagens aos vizinhos da horta, observou-se a admiração em relação ao empenho dos participantes. Uma das pessoas que mora nas adjacências afirmou que a presença da horta foi muito positiva para o bairro e para a cidade e sugeriu que a taxa de utilização da terra, aproximadamente $\mathrm{R} \$ 10.00$, já não deveria mais ser cobrada da equipe. Antigamente o espaço era tomado por entulho e demandava limpezas intermitentes com ônus excessivo ao poder público, e após a implantação da horta, benefícios como redução de gastos, vida ativa e com segurança, são destacados tanto pelos moradores quanto pela administração pública.

Um terceiro grupo abordado durante a visita foi das pessoas que vão até o local em busca de hortaliças frescas, livres de substâncias químicas e segundo eles, com preço mais acessível em relação aos supermercados e qualidade superior. Neste contexto, a primeira observação abstraída é que o conceito de cidade saudável, baseado nos determinantes sociais e alinhados aos princípios e valores de direitos humanos em uma convergência de políticas públicas para promoção da saúde, é perceptível na horta comunitária pela unanimidade nas respostas relacionadas à felicidade e qualidade de vida do grupo atuante, bem como da população adjacente e a consumidora. Estas percepções são evidências que a participação social, o empoderamento e a autonomia representativa alcançada por meio de atividades emancipadoras, a corresponsabilidade na tomada de decisões e a perspectiva relacional do lugar reverberam em ações que contribuem para mensurar qualitativamente se existem ou não mecanismos eficazes e eficientes na promoção do bem-estar dos munícipes e consequentemente, para construção de espaços saudáveis.

\subsection{A academia da saúde}

Após a visita à horta comunitária, os alunos foram conduzidos à academia da saúde onde foi possível vivenciar experiências de cidadãos que anteriormente ao projeto levavam uma vida sedentária e conviviam com patologias diversas e que atualmente alcançaram melhoria em seu condicionamento físico, coordenação motora e consequentemente, em sua motivação pessoal.

É importante destacar que a maioria dos frequentadores alega que se sentem saudáveis, ainda que o município conte com número reduzido de profissionais em determinadas especialidades da área da Saúde, como cardiologistas por exemplo. O projeto é uma evidência que a ação preventiva de um profissional de educação física pode garantir a redução de patologias de um determinado grupo. Nesta linha, De Leeuw and Green (2017), retomam o sugerido pela Alma Ata1, de que para atingir a sustentabilidade, a estratégia intersetorial de atenção primária preventiva é o melhor caminho, visando o envelhecimento ativo na expansão da vida livre de incapacidade, já que altos investimentos em serviços hospitalares são impraticáveis na maioria dos países. Como proposto pela Declaração Rio 922, o conceito e a prática de um planejamento urbano saudável promove a sustentabilidade centrada no ser humano.

\footnotetext{
1 Conferência Internacional sobre Cuidados Primários de Saúde Alma-Ata que aconteceu na extinta URSS, em Setembro de 1978.

2 A Declaração do Rio de 1992 foi uma Conferência promovida pelas Nações Unidas (ONU) onde foram elaborados importantes documentos sobre questões ambientais, como por exemplo, a Agenda 21.
}

(C) Labor \& Engenho, Campinas [SP] Brasil, v.12, n.4, p.482-494, out./dez. 2018. 
Em Conchal, esta assimilação de que a saúde não deve ser considerada o antônimo de doença foi contemplada em microescala. Além disto, outra evidência de promoção da saúde foi notada quando frequentadores relataram que mesmo com a presença do tráfico de drogas, a atuação do professor junto às pessoas que frequentam a praça e o projeto colabora para a sensação de segurança e a prevenção da violência no entorno imediato.

\subsection{A central de reciclagem}

No terceiro momento, os alunos foram apresentados a um projeto de cunho institucional que atinge diversas camadas da sociedade com foco na conscientização de crianças e adolescentes quanto aos processos de reciclagem e reutilização de materiais.

A liderança local apresentou a estrutura da central de reciclagem, sua operacionalização, organograma, cotidiano e os procedimentos de coleta, separação e prensagem de resíduos sólidos, e destacou a atuação do Poder Público na capacitação de discentes de toda a rede pública e particular de ensino fundamental quanto à coleta seletiva de lixo.

Durante diálogo com uma das profissionais da Central, foi relatado que a iniciativa pública de incluir jovens na tomada de decisões quanto à separação do lixo em suas residências tem sido mais eficaz que a tentativa de conscientização da população adulta. Destaca ainda o empenho da Prefeitura, independente das Gestões Políticas, em manter e melhorar a coleta de recicláveis nas escolas e nos chamados Eco Pontos.

Dentre as questões abordadas junto aos servidores municipais em relação ao projeto, é possível destacar a Geração de trabalho e renda, a importância do tratamento e reuso de Resíduos da Construção Civil (RCC), a compreensão da importância da função que desempenham e a promoção da interface entre o projeto e o Planejamento de Conchal.

Em conversa com os funcionários da central foi possível identificar que o consenso dentro do planejamento urbano ou nestes projetos comunitários pode ocorrer quanto ao tema, quanto aos objetivos e quanto aos resultados, porém o consenso quanto aos mecanismos e métodos para alcança-los não foi observado durante a visita.

\section{Noções de planejamento urbano em prática na comunidade}

Sob a ótica da leitura de artigos relacionados à ciência do Planejamento Urbano, é possível realizar uma análise comparativa com Conchal no contexto da ampla participação social representativa não apenas nos processos de planejamento, mas na percepção das políticas públicas como instrumentos eficazes para melhoria dos processos de urbanização e configuração do espaço urbano.

Segundo Robinson (2013,2016c), "podemos dedicar maior atenção em como "chegamos" às políticas urbanas do que em como "elas chegam" a algum lugar". Neste sentido, é possível admitir que em um primeiro momento, o olhar de gestores e planejadores é direcionado em criar mecanismos para melhoria da qualidade de vida, porém cabe a atenção em como identificar, por exemplo, se uma horta comunitária, uma academia da saúde ou uma central de reciclagem transmitem estas percepções de bem-estar e felicidade em determinada comunidade.

Ainda de acordo com Robinson (2016), "a invenção de conceitos e entendimentos do urbano pode emergir de qualquer lugar e ter ampla relevância em diferentes situações." Deste modo, ao seguir os caminhos da mobilidade de políticas públicas, também é possível criar uma trajetória para teorizar o contexto urbano criando conexões entre a produção e manutenção do espaço com a operacionalização e sistematização de projetos direcionados à promoção da saúde.

Ainda tomando como base conceitos de novas diretrizes e concepções para o desenvolvimento de projetos dentro de determinado processo de urbanização, Robinson (2018) apresenta alguns fenômenos que moldam espaços urbanos e que foram observados na visita à Conchal, dos quais é possível destacar: 
- A presença de hortas comunitárias em determinadas regiões do Município gera múltiplas conexões entre trabalhadores e consumidores, que acabam por moldar os lugares urbanos, inclusive no que se refere a evocar novos tipos de investigação, como a rotina de moradores que partem de regiões mais centrais em busca de hortaliças frescas em áreas mais suburbanas;

- Estas áreas mais suburbanas permitem o desenvolvimento de emergentes fenômenos, que constituem formas desarticuladas de urbanidade, dispersas de maneira desigual em relação à paisagem e design do Município;

- A variedade de locais periféricos ou suburbanos revela e molda os processos de urbanização contemporânea em um contexto dinâmico e transnacional, que também reformula a configuração e o significado desses locais;

Contudo, cabe a observação não apenas para o interior da cidade e de suas fronteiras, mas também a observação de sua exterioridade e os processos de tomada de decisão que moldam os processos de urbanização, fator determinante para pesquisadores e acadêmicos que trabalham com planejamento no contexto sul global dos países mais pobres.

\section{A governança saudável para a cidade}

Diante do que foi observado na Central de reciclagem, ficaram nítidas quão complexas e vulneráveis são as relações que permeiam o cotidiano e evidente que para uma cidade permanecer saudável, o princípio da governança é fator preponderante. De acordo com Barten (2011), a governança é o processo de tomada de decisão coletiva em que no centro do sistema está a equidade e que, constantemente, recebe influência de fatores culturais, geográficos e econômicos.

Devido às inúmeras escalas de interferências a qual a sociedade está submetida, para que a governança seja assegurada é fundamental que haja inclusão e fortalecimento da participação social, boa comunicação, senso de pertencimento, reconhecimento, representatividade e consolidação de parcerias.

Em macro escala, Barten (2011) sugere que a transdisciplinaridade - a reconexão entre áreas do planejamento urbano, ciências sociais e saúde pública - é essencial para atingir bons níveis de governança local e que deve contribuir também para a compreensão da mudança política global para o aumento da igualdade na saúde urbana.

\section{Evidências do caminho para a cidade saudável}

A partir da compreensão etimológica da palavra evidência e sua utilização nas áreas do planejamento urbano, é possível determinar e enxergar com clareza fatores presentes nas conversas e histórias da comunidade que se conectam com valores e princípios da promoção da saúde. Por exemplo, não ficam dúvidas quanto à efetiva participação multidisciplinar da sociedade nos projetos manifestada a partir da fala dos participantes da horta, academia e central de reciclagem, que mais adiante serão reproduzidas.

Neste sentido, é válido o destaque para três aspectos: a situação ou problema, os prognósticos e os resultados alcançados. Nos projetos visitados esta observação ocorreu de forma linear quando foram analisados os contextos físicos e históricos das regiões anterior aos projetos (situação/problema), quando foram identificadas as necessidades da população (prognóstico) e os objetivos atingidos com a aplicação dos programas (resultados). Em artigo relacionado à arte de aplicar o conhecimento científico na prática clínica, Lopes (2000) aborda este conceito dentro do contexto da Medicina Baseada em Evidências, unindo três elementos, problema (P), prognóstico (P) e resultado $(\mathrm{R})$ e ressaltando que a boa prática médica requer integração da ciência e da arte. No contexto do planejamento urbano participativo transdisciplinar, a boa prática também deve ser premissa para possibilitar a visualização e compreensão das evidências.

As abordagens e conversas descritas denotaram reações diversas e alguns registros fotográficos demonstram, ainda que em microescala, a qualidade de vida e a presença de fatores determinantes da saúde no Município de Conchal. 
Durante a visita, a unanimidade nas respostas no que se refere à felicidade, ao nível de satisfação com a realidade local e ao sentimento de pertencimento, aliadas aos sorrisos espontâneos obtidos durante as conversas demonstram o bem-estar presente na comunidade. Qualitativamente é possível mensurar através dos momentos vivenciados durante algumas horas, que as pessoas que participam de cada um dos projetos, ainda que tenham particularidades e ressalvas com questões específicas, na sua simplicidade se sentem comtempladas em suas necessidades e transmitem alegria e motivação.

Deste modo, em cada um dos projetos foi possível encontrar evidências de uma cidade saudável nos diálogos com a comunidade. Na horta comunitária, a participação social e o senso de pertencimento estão presentes claramente tanto por parte dos horticultores quanto dos moradores e consumidores, além da Governança dentro do conselho municipal. Uma das fundadoras da horta se auto avalia com nota dez, porque além de consumir o que cultiva, doa aos amigos e familiares e comercializa com pessoas de toda a cidade, além de ajudar e receber apoio dos demais participantes no espaço. Outro horticultor relata: "As pessoas se alimentam melhor depois da horta, vem gente até de fora da cidade para comprar porque aqui não tem agrotóxico" (Cuidador da Horta Planalto 2018).

Em uma segunda abordagem no interior da horta, ainda na temática da participação e da representatividade dos envolvidos, a mesma horticultora que se auto avaliou afirma: "Sim, existem as lideranças, mas as pessoas que cuidam do lugar é que tomam suas decisões". Na abordagem quanto sua aproximação em relação aos vizinhos após o projeto ela destaca: "Me tornei mais próxima daqueles que cuidam de um espaço aqui na horta" (Cuidador da Horta Planalto 2018).

No entorno da horta imediato, uma senhora quando relata as benfeitorias do espaço para o bairro e para a cidade cita inclusive a melhoria na disposição e qualidade de vida de seu marido que trabalha no cultivo.

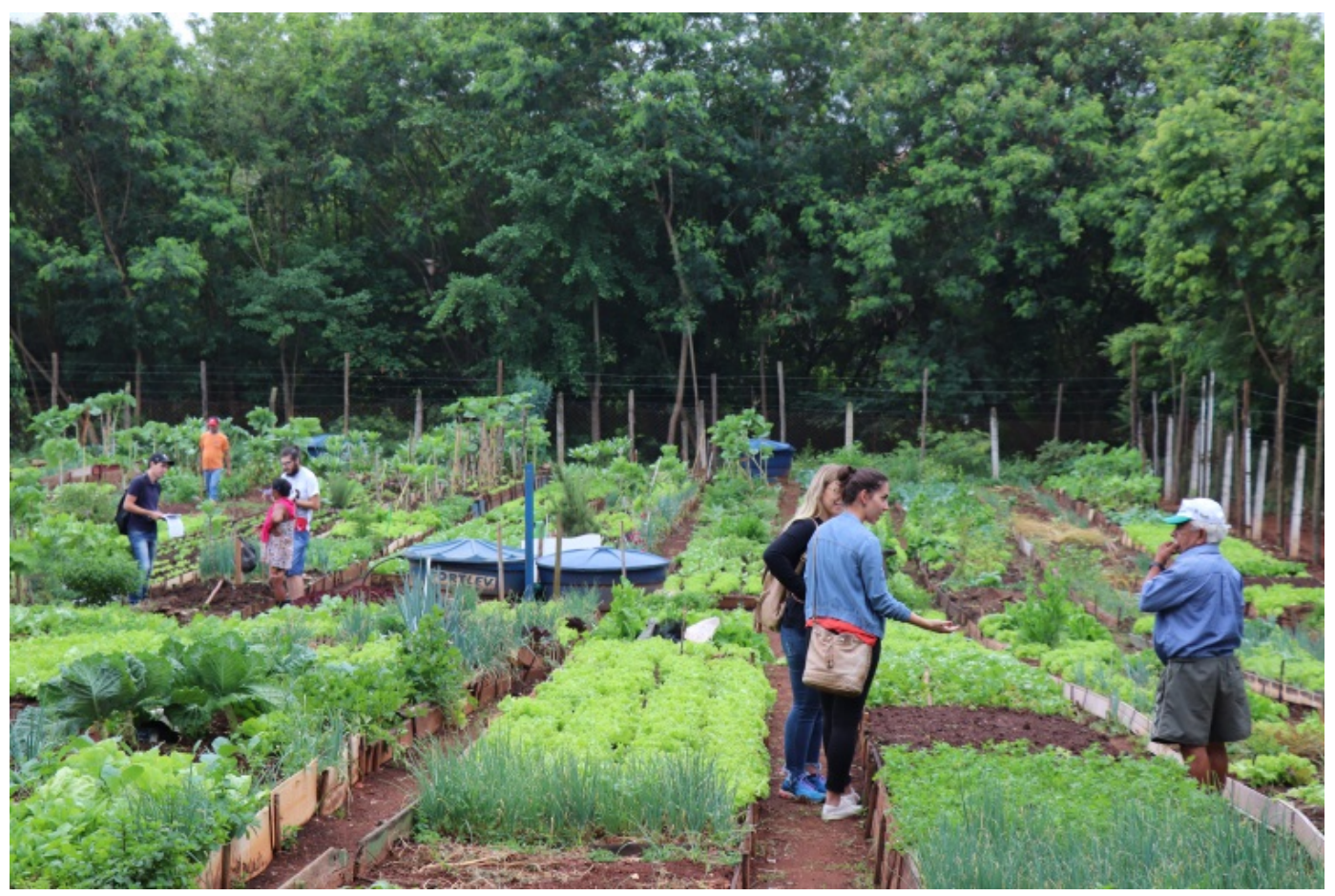

Figura 1. Interação entre estudantes e participantes da Horta Comunitária em Conchal. Outubro, 2018. Fonte: Fotos do LABINUR

Na academia da saúde a percepção de promoção da saúde foi ainda mais evidente já que os resultados refletem diretamente na qualidade de vida dos participantes. Um dos primeiros a se manifestar impressionou com o seguinte relato: "Quando comecei as atividades no espaço comunitário, mal conseguia sentar sozinho e depois de oito meses passei a vir até aqui de bicicleta" (Participante da Academia da Saúde), retomando parte de sua confiança, autonomia e motivação para viver. 


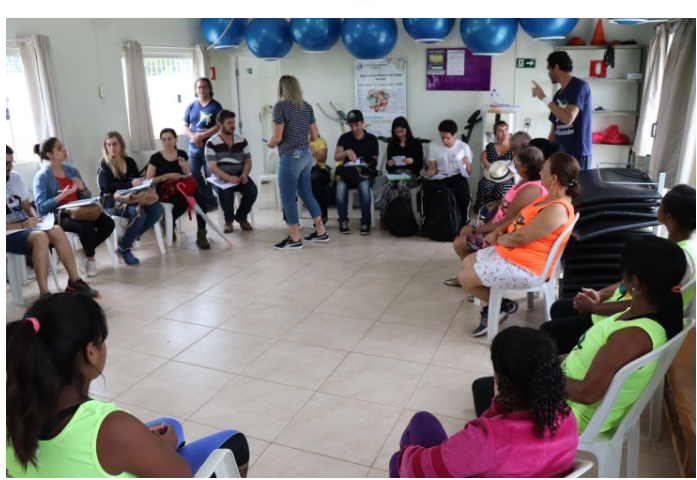

Figura 2. Roda de conversa com participantes e o professor da Academia da Saúde. Outubro, 2018. Fonte: Fotos do LABINUR.

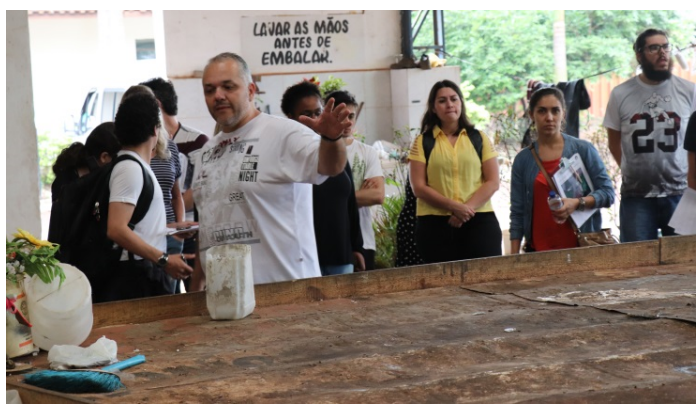

Figura 3. Líder da Central de Reciclagem explicando os processos aos alunos. Outubro, 2018. Fonte: Fotos do LABINUR.

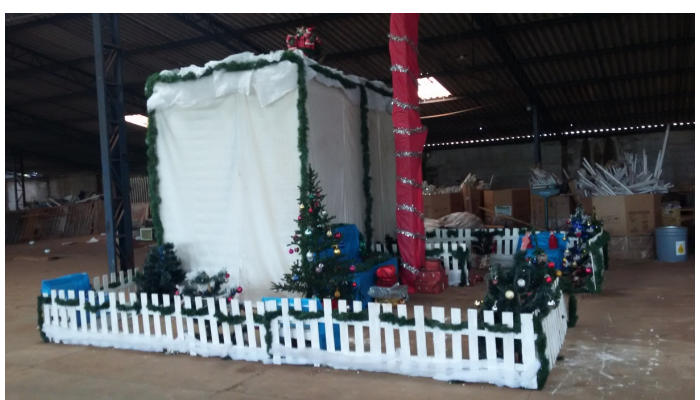

Figura 4. Montagem de espaço natalino com recicláveis por funcionário da central. Outubro, 2018. Fonte: Fotos do LABINUR.
Na central de reciclagem, a conversa com um servidor estatutário que trabalha na separação exemplifica as evidências de representatividade, liderança e trabalho com propósito. No primeiro momento, o trabalhador pontua sua participação como sendo muito boa, afirmando: "estou cuidando do meio ambiente". Em seguida, quando questionado sobre o ambiente de trabalho, relata: "não me dou bem com um funcionário mais velho daqui, ele acha que sabe mais que todos, mas o líder é muito bom e consegue organizar as coisas, fica cada um na sua e dá certo" (Funcionário Público estatutário da central, 2018).

Quando o assunto passou para a cidade e sua percepção do que mudou na região após a implantação da central de reciclagem foi direto: "a consciência da população de uma maneira geral”. Já no final do diálogo, quando a abordagem foi no sentido de procurar métodos para ficar saudável e feliz o separador afirma: "Utilizo minhas horas vagas na central de maneira criativa com a montagem do presépio de recicláveis".

Em um período de aproximadamente vinte minutos em frente ao espaço natalino foi possível identificar pelo menos quatro evidências no diálogo com o servidor de que neste projeto, em uma escala regional, existem fatores preeminentes que se exteriorizam na ascensão da qualidade de vida da população.

Como mencionado anteriormente, após a visita e com estas memórias e reflexões descritas, foram discutidos durante a aula diversos conceitos sob a ótica de cada estudante. As percepções individuais se convergiram entre os presentes e as palavras-chave foram correlacionadas com as experiências observadas na visita e distribuídas na lousa da sala conforme ilustração abaixo (Figura 5). Portanto, as palavras-chave encontradas na cidade, apreendidas pelos alunos e que se conectam com a legislação estudada, evidenciam o caminho de Conchal para uma cidade saudável.

Figura 5. Uma das lousas com as reflexões elaboradas pelos alunos após a visita e que deu origem a sistematização apresentada na Figura 6. Outubro, 2018. Fonte: Aula da disciplina de Planejamento Urbano como Promotor da Cidade Saudável, FEC/UNICAMP.

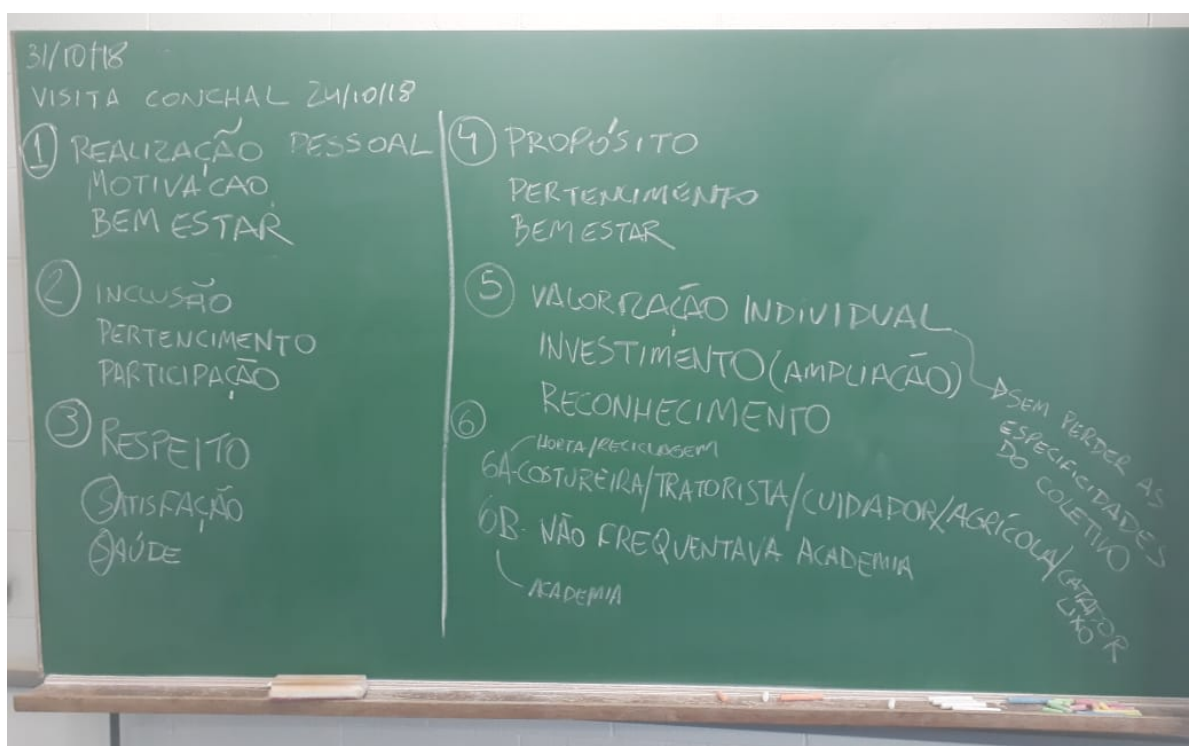


Através desta vivência em campo e sala de aula, foi possível identificar e sistematizar (Figura 6) as ações coletivas e experiências que valorizam princípios e valores do planejamento urbano para uma cidade saudável. Em suma, é evidente na horta comunitária que o conselho exerce papel fundamental de representatividade e estimula o fortalecimento e autonomia social; na academia, a assiduidade consciente dos participantes; na central de reciclagem, a conscientização da comunidade para reciclar, reutilizar e consequentemente reduzir a produção de resíduos como acontece, por exemplo, com a coleta de materiais higiênicos em escolas do município para produção de novos materiais com finalidades diversas.

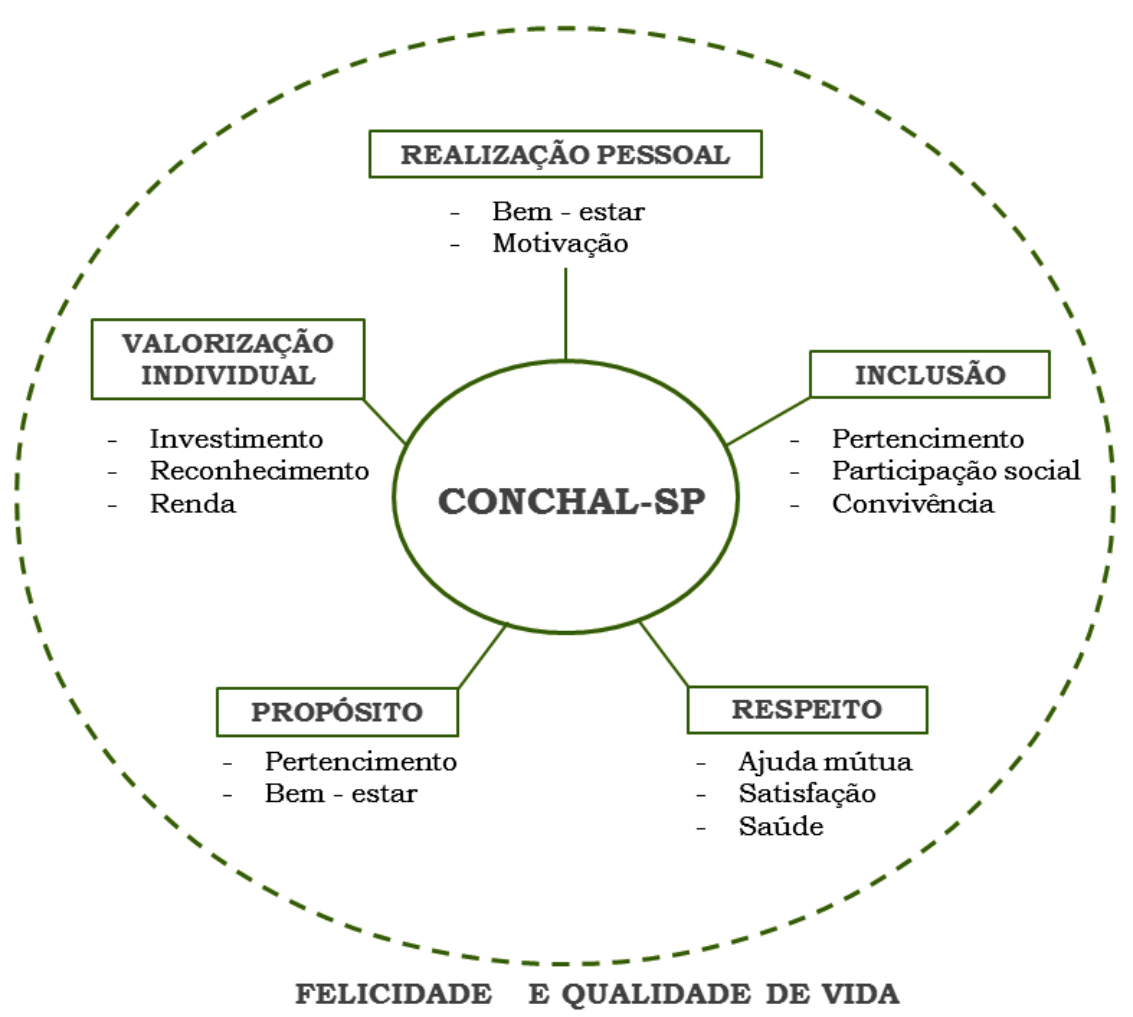

Figura 6. Sistematização das palavras-chave encontradas na comunidade e baseada nas reflexões desenvolvidas em sala de aula pós visita a cidade de Conchal/SP que evidenciam o caminho para cidade saudável (Outubro, 2018).

Fonte: Aula da disciplina de Planejamento Urbano como Promotor da Cidade Saudável, FEC/UNICAMP.

Outro ponto em comum significativo entre os três projetos foi a forte presença de lideranças formando parcerias eficazes e uma rede de suporte comunitária que confere aos projetos legitimidade, independentemente de interesses políticos, e que estão seriamente engajadas na construção de uma governança urbana participativa e inclusiva, desenvolvendo, como define Sperandio (2018), "governabilidade com governança para e com a sociedade no tecer de uma cidade saudável". Assim, torna-se provável o surgimento de novas lideranças com consciência coletiva.

Em todos os projetos visitados, existem divergências entre os profissionais atuantes, e neste sentido, o papel das lideranças é destacado como fundamental para o bom funcionamento do processo. Com uma visão estruturada conseguem compreender, por exemplo, que mesmo com alguns problemas como o tratamento da água, o município conta com ações integradas em prol da qualidade de vida de seus habitantes. Neste contexto, um dos funcionários que trabalha na prensa de resíduos afirmou que a água distribuída na cidade não é das melhores, mas ressaltou a importância do tratamento e reuso de resíduos para efetivação do Planejamento Urbano como resposta às demandas sociais da população.

\section{As conexões entre planejamento urbano e a cidade saudável.}

De maneira geral, durante a visita e após o diálogo, a comunidade avaliou a implantação dos três projetos de forma positiva, sendo inegável que os espaços atualmente são mais bem cuidados e seguros, aproximam as pessoas e tornam as relações mais coesas, fortalecem e desenvolvem a 
economia local, a cooperação mútua, a autonomia, o senso de pertencimento, a conscientização sobre o meio-ambiente e o bem-estar físico-psicológico. Neste sentido, é notório como ações estratégicas promovidas pelo planejamento urbano em vazios urbanos e espaços subutilizados proporcionam relevante impacto social, contribuindo para a melhoria da qualidade de vida e a promoção da saúde.

Ficou nítida nesta experiência a importância do apoio da administração municipal independente da troca de gestão, que ocorre no Brasil a cada quatro anos no âmbito municipal. 0 desenvolvimento de um programa de governo único e integrado fornece subsídios aos gestores, aos acadêmicos, e a sociedade para a manutenção do projeto que considera a promoção da saúde como balizador de qualidade de vida.

Desta maneira, indicadores significativos da avaliação de municípios saudáveis descritos por Brandão (2010) são perceptíveis na cidade de Conchal dentre os quais se destacam o fortalecimento da capacidade civil como estratégia para tomada de decisão e o conhecimento de suas responsabilidades sociais, além da disseminação da experiência realizada dando visibilidade às construções inovadoras, tornando-as reais e promovendo o intercâmbio entre redes regionais, nacionais e internacionais de municípios saudáveis.

É pertinente o debate para construção de um novo modelo de Planejamento Urbano que interdisciplinarmente, através de ações intersetoriais, pode fazer emergir a capacitação da população para troca de experiências com gestores e Universidade, além de contribuir no desenvolvimento de metodologias para monitoramento e avaliação dos objetivos propostos no Planejamento do Município, inclusive no que dispõe o Plano Diretor estratégico do Município de Conchal (2006).

Devido à complexidade em se desenvolver e se sustentar, o método de avaliação de cidades saudáveis é extremamente pertinente. Neste contexto, De Leew e Green (2017) buscam desenvolver políticas baseadas na metodologia $4 \mathrm{GE}^{3}$ por meio de avaliações realistas e pesquisas de ação reflexiva comunitária. 0 objetivo é esclarecer aos tomadores de decisão sobre estratégias para maximizar a saúde de suas populações urbanas e orientar decisões de investimento.

Este modelo dinâmico apresenta um caminho que vincula pré-requisitos, como liderança, estratégia, estruturas, processos e redes através de atividades como, por exemplo, políticas, programas e projetos que devem fazer a diferença ao status de cidade. Desta forma, como afirma Brandão (2010):

Somente a partir da ação sincrônica e articulada sobre as três esferas fundamentais da municipalidade, que são a gestão, a participação comunitária e os serviços públicos é possível construir e manter municípios potencialmente saudáveis (Brandão, 2010).

Nessa linha, foram desenvolvidos durante a disciplina infográficos com as percepções dos valores e princípios determinantes para a promoção da saúde. A coletânea destas percepções resultou em uma imagem que reflete os sentimentos identificados em Conchal. Na imagem a seguir, o Homem Vitruviano de Leonardo Da Vinci representa a humanização, o conjunto e o planejamento urbano através destes valores e princípios definidos nas legislações (Lei 8080 e PNPS). A humanização foi dividida entre cabeça, membros superiores e inferiores, sendo a cabeça a representação do princípio de autonomia, os braços são os objetivos a serem atingidos através dos valores de corresponsabilidade, autonomia e empoderamento, enquanto as pernas são os mecanismos de participação comunitária para alcançar esses objetivos, ou seja, todos caminhando juntos. A partir destes, surge a ideia de apropriação do planejamento urbano como um instrumento para potencializar conceitos como a felicidade, atribuída como auto avaliação da satisfação, termo que consta no Artigo 3oㅡ. Inciso II, da Portaria 2446 de 2014. Para tal, a auto avaliação de felicidade foi inserida no centro da figura como o eixo norteador do coração do Homem, e logo abaixo, na região do pulmão, aparece a governança, responsável pela manutenção

\footnotetext{
${ }^{3}$ A metodologia 4GE refere-se à avaliação de 4⿳a a geração desenvolvida dentro da estrutura de Cidades Saudáveis. É um processo participativo, dialético e pós-moderno que considera o consenso sobre parâmetros de avaliação, seu uso e resultados esperados.
} 
de o todo sistema. A partir dos mecanismos de participação comunitária, representados pelas pernas, deriva-se para itens como a inclusão, equidade, solidariedade, democratização e respeito à diversidade, sempre pautados em serviços públicos de qualidade, na gestão pública democrática participativa da cidade e na investigação da academia.

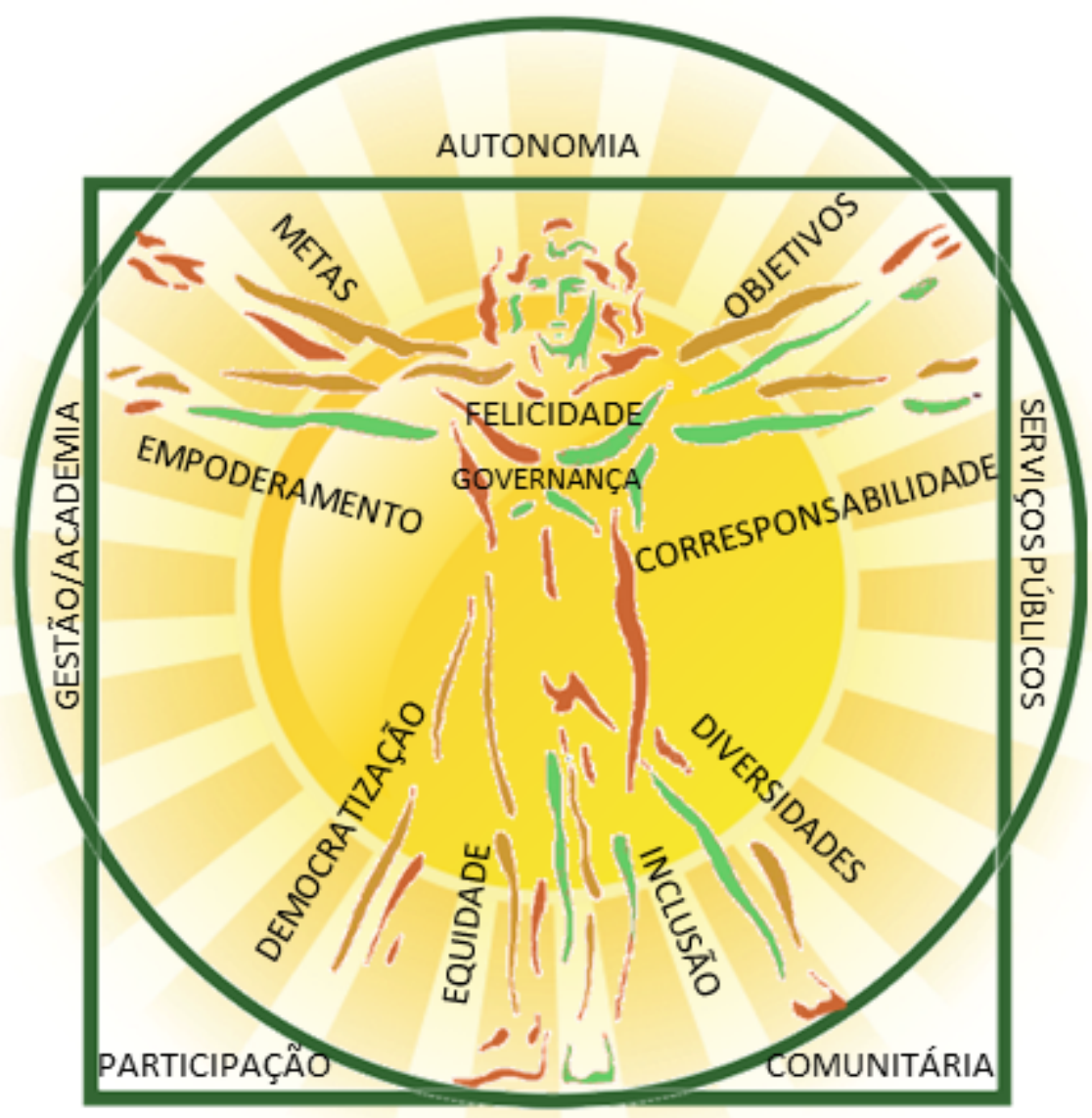

Figura 7. Infográfico de Valores e Princípios.

Fonte: Aula da disciplina de Planejamento Urbano como Promotor da Cidade Saudável, FEC/UNICAMP.

Este infográfico com suas explicações podem ser identificados na fala de diversos participantes entrevistados, aqui se destaca a contribuição feita por um horticultor de 74 anos: "Só pretendo parar de trabalhar aqui quando morrer, porque eu ajudei a tirar as pedras do terreno para essa horta nascer" (Participante da Horta Planalto, Outubro de 2018). Em um segundo momento quando questionado sobre a importância da atuação do Conselho para a horta e sobre sua participação ativa, fez uma analogia ao período eleitoral vigente: "Onde duas pessoas estão conversando sobre política, só posso participar se eu votar. Por isso, mesmo não precisando mais eu continuo votando, para poder conversar".

\section{Considerações finais}

A disciplina "Planejamento Urbano como Promotor de Cidade Saudável" do Programa de PósGraduação em Arquitetura, Tecnologia e Cidade ofereceu a oportunidade de desenvolvimento e capacitação de futuros mestres em uma recente concepção de conexão entre planejamento urbano e cidade saudável. Para atender às novas demandas da sociedade civil, as perspectivas do planejamento e para a construção de um novo modo de pensar municípios, é necessário habilitar e capacitar os pós-graduandos, gestores e comunidade para o pensamento crítico, reflexivo e criativo, objetivando a construção das boas práticas para cidades potencialmente saudáveis. Nesse aspecto, o apoio e incentivo do Laboratório de Investigações Urbanas da UNICAMP, possui importância vital na formação de concepções inovadoras de Planejamento Urbano, de Cidades Potencialmente Saudáveis e na interlocução entre diferentes escalas e agentes sociais. Tais concepções foram identificadas em Conchal [SP] tanto no que e refere à construção de políticas públicas saudáveis quanto na promoção da saúde e na participação social. 
Conforme Brandão (2010), cada ação realizada concorre para que as pessoas se apropriem mais do seu modo de vida comunitário, a medida que refletem sobre a realidade que as circunda e da qual fazem parte.

Através dos registros baseados nos relatos feitos pelos trabalhadores e moradores da cidade e da observação participante, notou-se a abrangência da reverberação destas ações de forma intra e intermunicipal.

Além disso, De Leeuw (2017) afirma que as cidades e suas ações constituem um laboratório vivo e único de inovação em saúde em nível local e, portanto, para que se mantenha saudável, alguns instrumentos-chave de monitoramento e avaliação são necessários, como por exemplo, a abordagem avaliativa baseada em teoria que valoriza e destaca as particularidades de cada cidade; a síntese das evidências encontradas pelas respostas fornecidas que esboçam a imagem de como estão funcionando; e o relatório anual que permite ao menos quatro anos de informações coletadas, facilitando uma análise de séries temporais da dinâmica da cidade saudável.

Dentre os fatores determinantes estudados nas legislações, foi possível observar no estudo de caso que a conexão entre o planejamento urbano e a promoção da saúde se dá principalmente nas seguintes áreas: Meio Ambiente, através da reciclagem de resíduos sólidos e utilização consciente do solo; Participação Popular, através da geração de emprego e renda; Saúde, através do incentivo às atividades físicas e no estimulo à alimentação saudável.

Contudo, é possível afirmar que a Universidade pode aprimorar junto ao poder público municipal, mecanismos de monitoramento aos projetos para garantir a permanência de Conchal como Município potencialmente saudável. Nesta linha, como propõe Corburn (2017), pensar o planejamento urbano saudável vai exigir novos comprometimentos para promover saúde e justiça social dentro da governança urbana e assegurar uma distribuição mais equitativa das características físicas e sociais positivas de cada realidade.

Portanto, um dos grandes desafios do planejamento urbano saudável está em desenvolver as cidades por meio de estratégias e políticas públicas que considerem a perspectiva histórica, as necessidades, as potencialidades locais e as gerações futuras e assim, permita o resgate da cidade por meio da interação simbiótica de forma sustentável entre as pessoas e o ambiente em quem vivem (Corburn, 2017).

Devido à complexidade do tema, é imprescindível a apropriação de formas interdisciplinares de conhecimento, a cooperação e corresponsabilidades entre diversos setores enfatizando a transversalidade como diferencial para o desenvolvimento e fortalecimento social.

\section{Referências}

Barten, F., Akerman, M., Becker, D. et al. (2011). Rights, Knowledge, and Governance for Improved Health Equity in Urban Settings. Journal of Urban Health: Bulletin of the New York Academy of Medicine, Vol. 88, No. 5.

Brandão, I. R. (2010). Na Trilha do Município Saudável. In: A.M.G. Sperandio, D.G. Machín, \& M.A.B. Fortunato (orgs.), Políticas Integradas em Rede e Construção de Espaços Saudáveis: Boas Práticas para a Iniciativa dos Rostos, Vozes e Lugares (pp. 31-57). Brasília: OPAS - Organização Pan-Americana da Saúde.

Brasil. Lei no 10.257, de 10 de julho de 2001. Regulamenta os art. 182 e 183 da Constituição Federal, estabelece diretrizes gerais da política urbana e dá outras providências. Diário Oficial da União, jul. 2001.

Brasil. Lei no 8.080, de 19 de setembro de 1990. Lei Orgânica da Saúde. Dispõe sobre as condições para a promoção, proteção e recuperação da saúde, a organização e o funcionamento dos serviços correspondentes e dá outras providências. Brasília, set. 1990.

Brasil. Portaria no 2.446, de 11 de novembro de 2014. Redefine a Política Nacional de Promoção da Saúde (PNPS). Disponível em: <http://www.brasilsus.com.br/index.php/legislacoes/gabinete-do-ministro/1049-2446>. Acesso em 25 nov. 2018. 
Certeau, M. (1998). A invenção do cotidiano - artes de fazer. Petrópolis: Editora Vozes.

Conchal. Lei complementar n. 157 de 10 de outubro de 2006. Dispõe sobre o Plano Diretor Estratégico do Município de Conchal, SP - PDEC e dá outras providências. Recuperado de: <http://www.conchal.sp.gov.br/ source/orgaos/planejamento/planoDiretor>.

Corbrun, J. (2017). Equitable and Healthy City Planning: Towards Healthy Urban Governance In the Century of the City. In: E. de Leeuw \& J. Simos (editores). Healthy Cities: The Theory, Policy, and Practice of Value-Based Urban Planning. Springer.

IPEA (2015). Desenvolvimento de metodologia de avaliação pós-ocupação em unidades habitacionais na cidade de Uberlândia, pertencentes à primeira fase do MCMV, enfocando aspectos funcionais, comportamentais $e$ ambientais. Governo Federal, Rio de Janeiro. Recuperado de: <http://repositorio.ipea.gov.br/bitstream/ 11058/7477/1/RP_Desenvolvimento_2015.pdf>.

Leeuw, E. de, \& Green, G. (2017). The Logic of Method for Evaluating Healthy Cities. In: E. de Leeuw, \& J. Simos (editores), Healthy Cities: The Theory, Policy, and Practice of Value-Based Urban Planning. Springer.

Lopes, A. A. (2000). Medicina Baseada em Evidências: a arte de aplicar o conhecimento científico na prática clínica. Rev Ass Med Brasil, 46(3): 285-8. Recuperado de: < http://www.scielo.br/pdf/\%0D/ramb/ v46n3/3089.pdf>.

RMPS - Rede de Municípios Potencialmente Saudáveis, Recuperado de: <https://www.paho.org/bra/ index.php? option=com_content\&view=article\&id=167:rede-de-municipios-potencialmentesaudaveisrmps\&Itemid=875>.

Robinson, J. (2016). Thinking cities through elsewhere: Comparative tactics for a more global urban studies. Progress in Human Geography, 40 (1) pp. 3-29. Recuperado de: <https://journals.sagepub.com/doi/ 10.1177/0309132515598025>.

Robinson, J. (2016). Ciudades en un mundo de ciudades: el gesto comparativo Andamios. Revista de Investigación Social, 13(32), septiembre-diciembre, pp. 163-210 Universidad Autónoma de la Ciudad de México Distrito Federal, México. Recuperado de: <https://www.redalyc.org/pdf/628/62847468008.pdf>.

Robinson, J. (2018). Comparando a mobilidade das políticas públicas: processos de urbanização, instâncias repetidas e topologias. Recuperado de <http://bibliotecadigital.fgv.br/ojs/index.php/rap/article/view/ $74660 / 71501>$.

Sperandio, A.M.G. (2018). Direito à cidade saudável: estratégias convergentes de promoção da saúde e planejamento urbano. Revista Intellectus, 45(1).

Sperandio, A. M. G., Francisco Filho, L. L., Guarnieri, et al. (2016). A interdisciplinaridade e o desenvolvimento de uma cidade saudável. In: Anais PLURIS, 2016. Maceió, AL, Brasil. 